\title{
METHODOLOGICAL ASPECTS OF ATTEMPTS TO TRANS-DIFFERENTIATE ADULT STEM CELLS INTO EMBRYONIC-LIKE CELLS IN VITRO.
}

\author{
Petr Uher ${ }^{\mathrm{a}}$, Petra Baborova ${ }^{\mathrm{a}}$, Renata Huttelova ${ }^{\mathrm{a}}$, Milena Kralickova ${ }^{\mathrm{a}, \mathrm{b} *}$, \\ Pierre Vanderzwalmen ${ }^{c}$, Nicolas Zech ${ }^{c}$
}

\author{
a Institute of Reproductive Medicine and Endocrinology, B. Smetany 2, 30177 Pilsen, Czech Republic \\ ${ }^{b}$ Department of Histology and Embryology, Faculty of Medicine in Plzen, Charles University in Prague, Karlovarská 48, \\ Plzeň, Czech Republic, CZ-301 66; \\ c Centre Hospitalier Inter Regional Cavell (CHIREC), Braine l'àlleud, Brussels, Belgium. \\ e-mail:M.Kralickova@seznam.cz
}

Received: April 18, 2008; Accepted: May 10, 2008

Key words: Haematopoietic stem cells/Mouse embryonic stem cells/Trans-differentiation/Regenerative medicine

Aims: The aim of this research was to set up an in vitro system to trans-differentiate haematopoietic stem cells (HSCs) into embryo-like stem cells in order to de-differentiate them. In this more naive state they should be cultivated more easily in order to augment them for consecutive differentiation and autologous transplantation for use in clinical practice.

Methods: Using the principle of the methodology of blastocyst injection, HSCs were co-cultivated with mouse embryonic stem cells ( $\mathrm{mES}$ ) with and without cell to cell contact. After co-cultivation HSCs were analyzed by flowcytometry using haematopoietic markers (CD34, CD45, CD133) and embryonic stem cell markers (SSEA-4, Tra-1-60, Tra-1-81).

Results: No ES cell markers were detected on the former HSCs. A decrease in HSC marker intensity was the only finding. This implies that no de-differentiation took place.

Conclusions: We hypothesize that the unnatural situation of a mixture of two cell types originating in different species may have led to this outcome. To achieve our goal of in vitro de-differentiation we need to use a purely human culture system without animal additives.

\section{INTRODUCTION}

Each new finding on stem cells raises hopes for their use in the clinical fields of regenerative medicine and transplantations. A few years ago, the finding of the transdifferentiation phenomenon was a major step forward in stem cell research ${ }^{1-8}$. This is the ability of tissue-specific stem cells to acquire the character of cell types different from the tissue of origin, regardless of germ layer origin. However, it is not definitely confirmed, whether there is true trans-differentiation in vivo or cell fusion, and what kind of biological relevance these phenomena have. It remains however, that trans-differentiation is a basic notion underlying the potential use of stem cells in the clinical field.

One interesting aspect of trans-differentiation is the possibility of influencing stem cells to become more naive, that is - to be "de-differentiated". De-differentiation occurs in vivo and in vitro. An indication for the capacity of adult stem cells to trans-/de-differentiate into an embryo-like state is seen in the model of blastocyst injection, where adult stem cells are injected into mouse blastocysts ${ }^{9}$. These cells take part in the development of the mouse. In such a chimeric mouse, derivatives of the former adult stem cells were found in several different tissues. This finding indicates that the adult stem cells must have been incorporated into the inner cell mass (ICM) of the blastocyst and de-differentiated as derivatives of the injected adult stem cells are not exclusively found in the tissue of origin. Injected cells have also been found in the epithelium of the gastrointestinal tract, the skin, the brain and other organs ${ }^{10,11}$. These experiments suggest that adult cells could become naive (embryo-like) in an embryonic surrounding.

The aim of the present experiments was to set up an in vitro system to trans-differentiate easily-accessible adult stem cells, haematopoietic stem cells (HSCs) from umbilical cord blood (UCB) into embryo-like stem cells and to establish a pool of cells for transplantation. In this more naive state it should be easier to cultivate and to increase them (because of their regained renewal potential, comparable with embryonic stem cells) for consecutive differentiation and autologous transplantation. Such dedifferentiated cells could also be a tool for investigating embryonic-like human stem cells without ethical or moral concerns.

\section{MATERIALS AND METHODS}

\section{Purification of umbilical cord blood stem cells.}

It has been shown that HSCs are highly enriched in the population of $\mathrm{CD} 34^{+}$cells ${ }^{2,12-14}$. For this reason we determine $\mathrm{CD} 34^{+}$cells as HSCs. Sodium citrate was added 
as an anticoagulant to the UCB. HSCs were then enriched by Ficoll density gradient purification ${ }^{15,16}$ followed by an immunomagnetic selection (Direct CD34 Progenitor Cell Isolation Kit, Midi-MACS System, Miltenyi Biotec, Bergisch Gladbach, Germany) for CD $34^{+}$cells. Their purity was determined by flow-cytometry.

\section{Flow-cytometry analysis of CD34+ cells.}

Flow-cytometry was performed on a FACSCalibur system (Becton Dickinson, Franklin Lakes, USA) and analysed with CELLQuestPro software (Becton Dickinson, Franklin Lakes, USA). Approximately $3 \times 10^{4}$ cells were acquired from each sample. Forward- and side-scatter plots were used to exclude dead cells and debris from the analysis after staining cells with $5 \mu \mathrm{l} / \mathrm{ml}$ of propidium iodide (PI). Necrosis correlates with a small decrease in forward scatter and in increase in side scatter of the PIpositive population whereas apoptosis is associated with a decrease in both forward scatter and side scatter of the PI-positive population. Dot plot analysis was used to estimate HSC purity and histogram analysis for estimating de-differentiation events. The following antibodies were applied for sorting HSCs: CD133/2-PE (Miltenyi Biotec, Bergisch Gladbach, Germany), CD34-PerCPCY5.5 (Becton Dickinson, Franklin Lakes, USA), and CD45-FITC (Becton Dickinson, Franklin Lakes, USA). Only fractions with $>90 \% \mathrm{CD}^{2} 4^{+}$were used for further experiments.

To check de-differentiation, the embryonic stem cell markers SSEA-4 (Chemicon, Temecula, CA), Tra-1-60 (Chemicon, Temecula, CA) and Tra-1-81 (Chemicon, Temecula, CA) were used, each linked with anti-mousebiotin (DakoCytomation, Glostrup, Denmark) and streptavidin-APC (Becton Dickinson, Franklin Lakes, USA). Adequate negative isotype controls were used in the experiments.

\section{Co-culture system.}

For co-cultivation Transwell ${ }^{\circledR}$ System (Corning, NY, USA) for a 6-well tissue culture plate was used. Different cell types are cultured in this system - grown in the same medium but separated by a membrane $(0.4 \mu \mathrm{m}$ pore $)$, permeable only to soluble molecules.

Experiment 1: Mouse embryonic stem cells (mES) (mES Sv129 provided by Dr. L. Schoonjans, KU Leuven, Belgium) were grown on feeder cells, mitotic inactivated mouse fibroblasts (MEF) in the lower compartment and HSCs $\left[1 \times 10^{5} / \mathrm{ml}\right]$ were cultured in the upper compartment. As control feeders without mES were grown in the lower compartment, the upper compartment was seeded with HSCs.

Experiment 2: Murine ES were replated before cocultured with HSCs.

Experiment 3: To allow cell to cell contact, the membrane was directly positioned on the mES. The mES cells were plated on gelatinised wells.

In all experiments the TX-WES medium (ThrombX,
Leuven, Belgium) charged with FCS (foetal calf serum) (10\%) and L-Glutamine (2 mM) was used.

\section{Immunocytochemistry.}

To check the differentiation status of mES, the cells were stained against alkaline phosphatase (AP) (Alkaline Phosphatase Substrat Kit III,Vector Laboratories, Inc., Burlingame, CA, USA), cytokeratin (EPOSTM Antihuman Cytokeratin/HRP; DakoCytomation, Glostrup, Denmark) and vimentin (EPOSTM Anti-Vimentin/HRP; DakoCytomation, Glostrup, Denmark). Mouse ES cells were fixed with paraformaldehyde (1\%) and then rinsed. According to the protocol recommended by the company, cells were stained with AP. After checking for the presence of AP, cells were stained for cytokeratin and vimentin. The fixed cells were blocked with mouse serum and then incubated with cytokeratin/HRP (1:10) and vimentin/HRP (1:10). After incubation the cells were rinsed and admixed with peroxidase substrate diaminobenzidine (DAB).

\section{RESULTS AND DISCUSSION}

The aim of the experiments was to set up an in vitro system to de-differentiate adult HSCs into embryonic like cells. Inspired by the generation of chimeras using blastocyst injection, the HSCs were co-cultivated with embryonic stem cells with and without cell to cell contact.

In the first experiment, co-cultivation of MEFs, mES cells and HSCs took place. With this experiment it was not possible to detect ES cell markers. Only the intensity of the HSC cell marker decreased. CD45 is more strongly expressed in HSCs than CD34 and CD133 and it was also the most stable marker. The intensity of CD34 and CD133 dropped more rapidly. No differences were seen whether co-cultivation was carried out with or without $\mathrm{mES}$ cells. Therefore it was reasonable to leave MEFs out of the co-culture, as the feeder cells may cover the effect of the mES cells.

In experiment 2 , mES were replated and their differentiation status was checked by staining against AP, cytokeratin and vimentin. The collagen matrix of the MEFs should support the growth of the mES without the influence of the soluble factors released by MEFs. Murine ES do not retain their embryonic status without MEFs for long. Therefore fresh replating had to be carried out once every day. The insert with the HSCs was placed every day into a fresh replated well. No ES cell markers were detected on the former HSCs, only a decrease of the HSCs marker intensity was noticed.

In recent years a series of reports ${ }^{17-21}$ have been published suggesting that trans-differentiation in co-culture experiments often needs a cell to cell contact between the different cell types. To take care of this, in the third experiment the cell to cell contact of mES and HSCs was allowed, MEFs were avoided. As in the previous experiments, only a decrease of the HSCs marker intensity was detected. Thus, in our setting, the cell to cell contact did 
not support the de-differentiation of the cells. Of note was the fact that mES differentiated faster when they were in direct contact with the membrane.

We hypothesize that the failure of our de-differentiation strategies is caused by the fact that the cells derived from different species. In the experiments two sorts of stem cells were used and each of them requires completely different environment for the maintenance in fundamental stage - the mESc need leukemia inhibitory factor (LIF) and HSCs need activin/nodal molecules ${ }^{22,23}$. To reach our goal of in vitro de-differentiation we will need to change our strategy towards a pure human culture system without any animal additives.

\section{LIST OF ABBREVIATIONS}

FCS - foetal calf serum

HSCs - haematopoietic stem cells

ICM - inner cell mass

LIF - leukemia inhibitory factor

MEFs - mitotic inactivated mouse fibroblasts

mES cells - mouse embryonic stem cells

hES cells - human embryonic stem cell

UCB - umbilical cord blood

\section{ACKNOWLEDGMENTS}

This study was supported by the Grant Agency of the Czech Republic, Grant No. 301/05/0078 and by Internal Grant Agency of Ministry of Health IGA MZd NR/ 9135-3. The authors would like to thank the team of Eccocell, A-8036 Graz, Austria, for providing cord blood and to thank Luc Schoonjans, Thromb-X, NV, C/O Center for Molecular and Vascular Biology, University of Leuven, Leuven, Belgium for his technical assistance.

\section{REFERENCES}

1. Ferrari G, Cusella-De Angelis G, Coletta M, Paolucci E, Stornaiuolo A, Cossu $\mathrm{G}$ et al. Muscle regeneration by bone marrow-derived myogenic progenitors. Science 1998; 279:1528-1530.

2. Bhatia M, Wang JC, Kapp U, Bonnet D, Dick JE. Purification of primitive human hematopoietic cells capable of repopulating immune-deficient mice. Proc Natl Acad Sci U S A 1997; 94:53205325.

3. Grompe M. Pancreatic-hepatic switches in vivo. Mech Dev 2003; 120:99-106.

4. Orlic D, Kajstura J, Chimenti S, Jakoniuk I, Anderson SM, Li B et al. Bone marrow cells regenerate infarcted myocardium. Nature 2001; 410:701-705.
5. Shen CN, Horb ME, Slack JM, Tosh D. Transdifferentiation of pancreas to liver. Mech Dev 2003; 120:107-116.

6. Bjornson CR, Rietze RL, Reynolds BA, Magli MC, Vescovi AL. Turning brain into blood: a hematopoietic fate adopted by adult neural stem cells in vivo. Science 1999; 283:534-537.

7. Austin TW, Lagasse E. Hepatic regeneration from hematopoietic stem cells. Mech Dev 2003; 120:131-135.

8. Karbanová J, Mokrý J, Kotingová L. Neural stem cells transplanted into intact brains as neurospheres form solid grafts composed of neurons, astrocytes and oligodendrocyte precursors. Biomed Pap Med Fac Univ Palacky Olomouc Czech Repub 2004; 148:217220.

9. Harder F, Henschler R, Junghahn I, Lamers MC, Muller AM. Human hematopoiesis in murine embryos after injecting human cord blood-derived hematopoietic stem cells into murine blastocysts. Blood 2002; 99:719-721.

10. Geiger H, Sick S, Bonifer C, Muller AM. Globin gene expression is reprogrammed in chimeras generated by injecting adult hematopoietic stem cells into mouse blastocysts. Cell 1998; 93:1055-1065.

11. Gardner RL. Contributions of blastocyst micromanipulation to the study of mammalian development. Bioessays 1998; 20:168-180.

12. Baum CM, Weissman IL, Tsukamoto AS, Buckle AM, Peault B. Isolation of a candidate human hematopoietic stem-cell population. Proc Natl Acad Sci U S A 1992; 89:2804-2808.

13. Osawa M, Hanada K, Hamada H, Nakauchi H. Long-term lymphohematopoietic reconstitution by a single CD34-low/negative hematopoietic stem cell. Science 1996; 273:242-245.

14. Pflumio F, Izac B, Katz A, Shultz LD, Vainchenker W, Coulombel L. Phenotype and function of human hematopoietic cells engrafting immune-deficient CB17-severe combined immunodeficiency mice and nonobese diabetic-severe combined immunodeficiency mice after transplantation of human cord blood mononuclear cells. Blood 1996; 88:3731-3740.

15. Gabbianelli M, Sargiacomo M, Pelosi E, Testa U, Isacchi G, Peschle C. "Pure" human hematopoietic progenitors: permissive action of basic fibroblast growth factor. Science 1990; 249:1561-1564.

16. Thoma SJ, Lamping CP, Ziegler BL. Phenotype analysis of hematopoietic CD34+ cell populations derived from human umbilical cord blood using flow cytometry and cDNA-polymerase chain reaction. Blood 1994; 83: 2103-2114.

17. Galli R, Borello U, Gritti A, Minasi MG, Bjornson C, Coletta M et al. Skeletal myogenic potential of human and mouse neural stem cells. Nat Neurosci 2000; 3:986-991.

18. Badorff C, Brandes RP, Popp R, Rupp S, Urbich C, Aicher A et al. Transdifferentiation of blood-derived human adult endothelial progenitor cells into functionally active cardiomyocytes. Circulation 2003; 107:1024-1032.

19. Wurmser AE, Nakashima K, Summers RG, Toni N, D'Amour KA, Lie DC. et al. Cell fusion-independent differentiation of neural stem cells to the endothelial lineage. Nature 2004; 430:350-356.

20. Mollah ZU, Aiba S, Manome H, Yoshino Y, Tagami H. Cord blood CD34+ cells differentiate into dermal dendritic cells in co-culture with cutaneous fibroblasts or stromal cells. J Invest Dermatol 2002; 118:450-460.

21. Ball SG, Shuttleworth AC, Kielty CM. Direct cell contact influences bone marrow mesenchymal stem cell fate. Int J Biochem Cell Biol 2004; 36:714-727.

22. Daheron L, Opitz SL, Zaehres H, Lensch WM, Andrews PW, Itskovitz-Eldor J et al. LIF/STAT3 signaling fails to maintain selfrenewal of human embryonic stem cells. Stem Cells 2004; 22:770778.

23. Koestenbauer S, Zech NH, Juch H, Vanderzwalmen P, Schoonjans L, Dohr G. Embryonic stem cells: similarities and differences between human and murine embryonic stem cells. Am J Reprod Immunol 2006; 55:169-180. 
